\title{
Choosing physics within a gendered power structure: The academic career in physics as a "deal"
}

\author{
Meytal Eran-Jona ${ }^{1, *}$ and Yosef Nir $\oplus^{2, \dagger}$ \\ ${ }^{1}$ Feinberg Graduate School, Weizmann Institute of Science, Rehovot, Israel 7610001 \\ ${ }^{2}$ Department of Particle Physics and Astrophysics, Weizmann Institute of Science, Rehovot, Israel 7610001
}

(Received 29 October 2020; accepted 14 June 2021; published 12 July 2021)

\begin{abstract}
This research focuses on the absence of women among academic staff in physics. To explore the causes of this gender imbalance, we focus on the decision-making junction between obtaining a Ph.D. diploma and pursuing a postdoctoral position. We use the mixed-methods paradigm, combining a nationwide representative survey of Ph.D. students in Israel ( $n=267$ respondents out of 404 questioned) and interviews with Ph.D. students and postdoctoral fellows $(n=38)$. The theoretical novelty that we propose is to view such career decision making as a "deal" that involves contextual, organizational, and individual variables and their intersection. Young women are examining the components of this deal: what it offers them and what prices they will have to pay, but their decision is made within a gendered power structure. Studying both context factors and agency, we reveal the multiple hidden ways in which gender operates as a power structure, putting up barriers to women's academic careers. This latent power structure influences women's decision making and experiences in several ways. In the academic field, it produces unequal competition in a male-dominated playground. In the social sphere, choosing a demanding academic career is seen as disrupting gender order. Within the family, women carry a greater burden of family work and give precedence to their husband's career and preferences. Within this social structure, women who decide to follow an academic career feel that they must excel, and this demand for "excellence" acts as a hidden mechanism within the gendered power structure that may prevent talented women from pursuing an academic career in physics.
\end{abstract}

DOI: 10.1103/PhysRevPhysEducRes.17.020101

\section{INTRODUCTION}

The small proportion of women among university students and academic staff in math-intensive disciplines is an issue of significant concern. In the last two decades, much research has focused on this subject, and much effort has been invested in trying to improve the situation. Of particular interest is the field of physics, where the gender imbalance in academia is particularly severe and where female participation has shown no significant increase despite dedicated efforts in the USA [1], Europe [2], and globally [3].

The present study focuses on gender imbalance in the physics field in Israeli academia. The percent of women among Israeli physics students and academic staff is even worse than in the USA and Western Europe: 16\% among graduate students and $6 \%$ among faculty members [4].

\footnotetext{
*meytal.jona@weizmann.ac.il

yosef.nir@weizmann.ac.il
}

Published by the American Physical Society under the terms of the Creative Commons Attribution 4.0 International license. Further distribution of this work must maintain attribution to the author(s) and the published article's title, journal citation, and DOI.
These low rates are even more striking when compared with other fields in Israeli academia, such as medicine, where women constitute $69 \%$ of graduate students and $35 \%$ of faculty members, or biology, where the proportions are $58 \%$ and $30 \%$, respectively.

Looking at the data, we asked ourselves why so few women pursue an academic career in physics. As a first step toward answering this question, we investigate the decision making of Israeli students, both male and female, when considering an academic career trajectory. Therefore, we pose the following three research questions: How do Ph.D. students perceive the academic career path? What are the considerations of female students for deciding whether to pursue a postdoctoral fellowship abroad? How are women's considerations for and against pursuing an academic career shaped (or constructed) by gender? To answer these questions, we use a mixed-methods research methodology that combines a representative quantitative survey of all physics Ph.D. students in Israel with qualitative tools and we conduct interviews with female Ph.D. students and postdoctoral fellows.

In this paper, we present the accounts of these young women, examine their considerations, and try to untangle the impact of their context-their personal, professional, economic, and family circles-on their decision making. 


\section{INTERSECTING KNOWLEDGE FIELDS}

Research that deals with the integration of women into academic careers is embedded in various academic disciplines that are mostly studied separately: psychology, sociology of education, sociology of organizations, gender studies, labor studies, economics, and others. The starting point for our study lies in the understanding that the answers to complex questions about barriers to women's integration in academia cannot be found in a single theoretical field or discipline. We must go beyond these traditional disciplinary borders toward interdisciplinary research, which can provide a diverse and multidimensional perspective to examine and answer these research questions.

The lack of interdisciplinary research among those dealing with career issues and the need to integrate different perspectives was highlighted as early as the 1970s [5]. The lack of interdisciplinary research in the field results in a partial and biased understanding of careers, so a multilayered approach is needed [6].

In response to this challenge, we study career decision making in physics as a multilayered and multidimensional phenomenon, combining in our analysis contextual, organizational, and individual variables and their intersection. Looking at both structure and agency, we view careers as not solely based on individual free choice, but rather on the intersection between individual choice, the roles and structure of physics as a field (in terms of Bourdieu), the gendered social expectations and norms, and the expected family division of role and employment.

\section{A. Gender and power}

The understanding that power is an integral part of gender relations is central to the feminist theory [7-11]. Power is an integral part of Scott's definition of "gender" [10], according to which "gender is not only a constitutive element of social relationships based on perceived differences between the sexes, but it is also a primary way of signifying relationships of power. Changes in the organization of social relationships always occur concurrently with changes in representations of power."

The idea that social structure and processes are gendered was developed in the feminist discourse starting in the early 1980s. Our theoretical starting point is based on the understanding that gender is a power structure in society, within the family, and in organizations [7,10,12-14].

In her book "Gender and Power" [7], Connell characterizes the elusive way in which power works in social relationships: "While particular transactions involving power are easy to observe, it is often difficult to see beyond individual acts of force or oppression to the structure of power, a set of social relations with some scope and permanence." This elusive social power may be "a balance of advantage or an inequality of resources in a workplace, a household, or a larger institution." Connell uses the term "gender regime" to analyze gender relations within the family $[7,14]$.

Acker claims that gender is a structural feature of labor organizations [13]. She proposes a theory of organizations and gender that follows Kanter [12] and other scholars $[7,10,15]$ who claim that gender is a structural feature of organizations and not a characteristic feature of individuals bringing it to the workplace. Acker shows how deeply gender is embedded within organizations. She claims that "the organizational structure is not gender-neutral. On the contrary, assumptions about gender underlie the documents and contracts used to construct organizations and to provide the commonsense ground for theorizing them." According to Acker, when we say that an organization is gender biased, it means that advantage and disadvantage, exploitation and control, action and emotion, and meaning and identity are all patterned through and in terms of a distinction between male and female.

Following these insights, we claim that gender acts as a power structure in academia, within the field of physics as a space of knowledge production and as a workplace, and within the family. As such, it produces and reproduces the career choices of young women.

Gender studies have changed over the last three decades in many ways, with a growing recognition of feminist thought and activism in the Global South, and the development of queer studies and trans studies, mainly in the USA [16]. Moreover, there is a wide understanding that gender should not be studied separately from other power structures. Therefore, the intersections of race, class, and gender have been widely accepted as an important aspect of feminist research and theory. The intersectionality perspective has developed from the critique of the hegemonic "white" feminist theory that was based on the experience of white women $[17,18]$. Scholars suggest new avenues to research and publicize the hidden stories at the intersections of race, ethnicity, gender, class, nation, and sexuality [18].

Upon examining the intersection between gender and ethnicity, one sees that class and religion are of importance also in the Israeli context. Israeli society is aligned along two main axes: religion and ethnicity. There are social gaps between religious and secular Jews, between Jews and Arabs, and between the geographical and social periphery and the center, and these axes are interconnected and also influence women in academia [19]. The field of physics remains, however, a very homogeneous field, consisting mostly of white male Jews of medium-high social-economic background and from educated families $[4,20]$.

\section{B. Physics as a social field}

Physics is a masculine field characterized by the supremacy of a white male majority; it has a masculine culture and a masculine public image [21]. The integration of women into this field is relatively new, and the gender 
imbalance in the field is significant worldwide [3]. Following Bourdieu's theory [22,23], we study physics as a social field, which is a patterned set of practices within a broader social space that suggests competent actions in conformity with rules and roles. It is a playground or battlefield in which actors, endowed with a certain fieldrelevant capital, try to advance their position.

Traweek [24] conducted an in-depth anthropological study of the world of physics, tracing the culture of high-energy physicists in one of the leading laboratories in the USA. Traweek describes physics as a male domain and claims that masculinity is an organizing principle of the physics laboratory, as part of the common perception that science is a field of "individual great men." The field of physics is highly competitive. To be accepted as a member of the physics community, one must be committed, charismatic, highly motivated, dominant, and aggressive. Only the strongest and brightest manage to overcome these obstacles or, in her words, "Only the blunt bright bastards make it." This culture of physics as a male-dominated field is also prominent in later studies [21,25].

One example of the gendered nature of organizations lies in the common gendered perception of the "ideal worker," which is based on the image of a man who is free from the burden of childcare and family and can therefore devote his entire time and energy to work [13]. Acker claims that occupations and hierarchies assume a universal, intangible employee. This employee is, in fact, a man: a man's body, masculine sexuality, control over emotions, and minimal responsibility for reproduction. Images of the male body and masculinity that are dominant in organizational processes marginalize women and contribute to the preservation of gender segregation in organizations.

This claim, which is certainly valid with regard to academic institutions, was established and took shape in an era when most staff members were men and most of their spouses were housewives. Bagihole and Goode [26] examine Acker's claims in the context of academia. They argue that there is a standard model of an academic career that is far from being gender neutral. Instead, it is embedded in a masculine culture and based on a patriarchal support system. Bailyn [27] studied the academic careers of senior female faculty at MIT. She argues that the belief, shared by female and male academics alike, is that the only way to be a first-rate scientist is to strive to be the ideal, perfect academic, for whom work is the total priority, and for whom there are no outside responsibilities and interests.

Benschop and Brouns [28], who examined gender aspects in academic institutions in Netherlands, claim that the basis of the scientific quality standard contains the "Olympus" model of science, in which the dominant representation of the brilliant researcher is that of a young man at the top of Mount Olympus, away from the practices of daily life, rooted in the ivory tower of academia. This model is one dimensional, gender biased, not open to variance, and may alienate women who do not identify with it.

The perception of a profession as masculine or feminine is also influenced by the extent to which an occupation allows or prevents one from combining family life with a career. For women who completed a Ph.D. in Israel with an excellent grade, this component was found to be a significant factor in their decision of whether to pursue an academic career in science [29].

Lamont and Molnar [30] review the idea of "boundaries" and how it explains various inequalities such as class, race, and gender. For the latter, they focus on how gender and sexual categories shape expectations and work life. In this context, boundaries are defined as "the complex structures-physical, social, ideological, and psychological - that establish the differences and commonalities between women and men, shaping and constraining the behavior and attitudes of each gender group" [31]. Violation of gender boundaries often leads to punishment and stigmatization in the workplace [32].

\section{Gender inequality}

The attempt to understand the preservation of inequality in academia in general, and in sciences in particular [science, technology, engineering, and math (STEM)], has given rise to a growing body of research. Current explanations deal with the conscious and unconscious processes that occur at the individual, organizational, and social levels.

These explanations can be divided into three categories: explanations concerning the preservation of the gendered power structure in society, including in organizations, that are also reflected in the field of science (see, e.g., Refs. [7,13]), explanations concerning organizational structures, processes, and practices in academia that are biased toward men, their way of life, and merits [33-35], and explanations concerning organizational culture and climate, which belong, to some extent, to the previous category, but deal more with conscious practices and behaviors that have a negative impact on women in academia (chilly climate, sexual harassment, and microaggressive behavior toward women) [36].

In the organizational context, studies found that the inequality in academia starts with recruitment and screening processes (the "similarity bias," activation of criteria fitting men such as the number of publications, and recommendation letters containing gender bias against women) and continues to include working conditions and job characteristics (women receive lower wages than their male colleagues, fewer research resources, funding is gender biased, as are staffing resources, etc.). Unequal practices also appear in promotion processes, which are biased in favor of men (e.g., the preservation of the "scissors curve," in which the proportion of women decreases as the positions become more senior) [29,33,34,37-39]. 


\section{Women's career decision making}

Women pursuing nontraditional careers face many obstacles and constraints that can limit or impede their career development. Those who wish to pursue an academic career in masculine fields must often overcome the absence of role models, weak self-efficacy beliefs, and uncertain outcome expectations along with cultural and institutional barriers.

Previous research focusing on STEM fields in academia reveals a high attrition rate for women before and during their postdoctoral studies, a key period leading to an academic career where the number of women decreases dramatically $[29,40,41]$.

Choosing an academic career path is risky. The results of a meta-analysis of research on 16 different types of risk taking indicate that male participants are more likely to accept almost all types of risks than are female participants [42]. The tendency of women to take fewer risks may be one of the explanations of the lower rates of women who choose the academic path, given its high demands and job insecurity.

The decision by women to pursue a nontraditional career path such as physics could also be explained (following social cognitive career theory $[43,44])$ by their lower selfefficacy (on average). The belief of a low level of selfefficacy in science among women has been implicated in contributing to the limited number of women earning post-graduate degrees and holding academic appointments [45-48]. Other factors that may explain a woman's choice not to pursue a career in physics include the imposter syndrome, gender-biased mentoring during graduate school [49], and the "two-body problem" [50].

However, these theories and explanations for decision making are partial and share the same problems as other sociological or psychological theories of career decision making (trait theory, the developmental model, and social learning theory, see Ref. [51]). All of these theories retain a strong sense of decision making being fundamentally an individual process that contains major elements of technical rationality and remains within the influence or control of individuals [51].

Following Bourdieu and others, we claim that the career decision making of women is affected by both their agency (i.e., their capacity as individuals to act independently of the social system and to make their own free choices) and context factors. The literature on decision making may help to understand women's considerations in choosing an academic career [52], but consent is never freely or neutrally given in situations of inequality [53].

Bourdieu's field theory [51,54-56] helps to better explain the power structures that influence women's decision making regarding an academic career. According to Bourdieu, agents do not continuously calculate according to explicit rational and economic criteria. Bourdieu uses the agency-structure bridging concept of field, in which a field is described as any historical, nonhomogeneous socialspatial arena in which people maneuver and struggle in pursuit of desirable resources. In his words, "it is the state of the relation of force between players that defines the structure of the field" [57]. The "players" within a field are various and have different resources and power, which make up "the relation of force." For Bourdieu, each stakeholder brings capital to the field, which can be economic, social, cultural, or symbolic.

However, as we learned from decades of sociological studies, these various types of capital are all gendered, and gender constitutes an asymmetric capital. Therefore, while masculinity operates in favor of men, femininity does not operate in favor of women [58]. Moreover, following Bourdieu's theory, the recognition of the limits of what is possible or not possible, encapsulated in the decisions of men and women, shapes their aspirations and career paths in a different way. Women's decision making is shaped within a gendered power structure.

\section{E. The Israeli context}

To understand the research context, we refer to Israeli society, which has certain special characteristics.

First, Israeli-Jewish society is a familial society. The importance of family is manifested in the relatively high number of children per family, and in the great importance attached to the family in the life of both the individual and the community [59]. The family is a central social institution in an individual's life and part of the national strength. A result of the centrality of the family is that the woman in the Israeli-Jewish family is perceived first and foremost as a mother and a wife, and only next as a provider [60].

Israelis marry on average at a relatively young age and have more children than women in other Western societies. The average fertility rate per woman in Israel is 2.7 children per woman (for all women excluding ultraorthodox Jews, who have a higher rate), which is a high rate compared with the overall average of 1.7 in OECD countries [61].

In Israel, most women are employed full-time and most maintain full-time employment even while raising their children. The rate of full-time employment for women in Israel $(68.2 \%)$ far exceeds the corresponding rate in other countries, such as Germany (54\%), Norway (60\%), the United Kingdom (57.7\%), and Netherlands (41.6\%) [62].

However, despite the large extent to which Israeli women participate in the labor market, and despite a discourse that promotes equality in the division of roles in the domestic sphere, the division of roles within Jewish-Israeli families and, in particular, the burden of raising children, remains unequal. Research on Israeli fathers found that, despite the increase in recent decades in the involvement by fathers in household chores and childcare, the parental responsibility in the private sphere remains feminine. Men spend longer hours at work, and most of the household chores and 
childcare become the burden of their wives [63]. These findings are in line with studies conducted in other Western countries (for example, in the USA and Canada; see, e.g., Ref. [64]) and with the research on women working in male-centric domains, experiencing daily battles between competing desires both to be a "caretaker" at home and to develop a professional career [65]. Family transformation in Israel is influenced by two contradictory trendspreservation versus innovation-with each pulling in a different direction [66].

In STEM fields in Israeli academia, women are also underrepresented. The lowest representation of women is in physics, with only $6 \%$ of the academic staff in physics being female [4]. However, the rates are also low in mathematics and computer studies (11\%), the physical and life sciences (13\%), and engineering and architecture (14\%) [67]. Kark [68] claims that the underrepresentation of women in STEM fields in Israel is a consequence of the compulsory military service that is biased toward males, the social norms of familialism, and the gendered care responsibilities.

\section{METHODOLOGY}

\section{A. Mixed-methods research paradigm}

This study uses the mixed-methods research paradigm, which is an intellectual and practical synthesis based on qualitative and quantitative research. Mixed-methods research recognizes the importance of traditional quantitative and qualitative research but also offers a powerful third paradigm choice to provide the most informative, complete, balanced, and useful research results [69-71]. In parallel, to structure the research tools and analyze the research findings, we use feminist research approaches and theories that provide the framework and tools for delving into the lives of women [72-74].

Within mixed-methods research, this paper is based mainly on qualitative-data collection and analysis, although it concurrently recognizes that the addition of quantitative data and approaches to the research contributes to a rigorous understanding of the social phenomena under study.

\section{B. Qualitative-data collection}

A series of surveys we conducted in 2018-2019 of all undergraduate and graduate physics students in Israel revealed that these students belong to a hegemonic group within Israeli society consisting mostly of white Jewish men of medium-high socioeconomic background and from educated families. Women form a minority of physics students in all degrees, with the rate hovering around $16 \%$ in all three degrees (B.Sc., M.Sc., and Ph.D.) over the last decade. The number of Arab students is even lower at just under $1 \%$ of the students. Ultraorthodox students are almost completely absent from physics. Another variable examined was gender self-definition: The vast majority of physics doctoral students defined themselves as either "male" or "female" (only three students defined themselves as "other"), so we did not have a sufficiently large group to explore this aspect $[4,20]$.

Thus, although we fully acknowledge the importance of examining the intersections between gender and other social categories, given that the field of physics in Israel lacks diversity in terms of religion, ethnicity, and status, we focus herein on examining the differences between women and men in physics as distinct categories.

The first stage of the research was qualitative. We conducted 25 in-depth interviews with female physics $\mathrm{Ph} . D$. students studying at six research universities in Israel [75]. Given the small size of the community (about 60 female physics Ph.D. students study in Israel in a given year), we had to reach out to many of them. The researchers communicated with the students first through an email request, following which we used personal connections within the physics community and the snowball methodology to obtain a high response rate. No student refused to be interviewed; some even agreed to be interviewed while on maternity leave. The interviews were conducted face to face in the students' offices or labs, and sometimes in their homes or at a coffee shop, depending on their request.

Overall, we interviewed 25 female physics Ph.D. students from 26 to 36 years of age. Most of them were married or in a relationship (21), and only a few were single (4). Twelve were mothers, with 1-4 children, mostly babies or toddlers. Fifteen were experimental physicists, and ten were theorists. Ten of their spouses were engaged in the fields of computers, engineering, or other "exact" sciences in the industrial or private sector, eight were Ph.D. students in physics, and the remaining had other occupations.

To understand the next phase of the academic career, the postdoctoral path, we also conducted 13 interviews with Israeli female postdoctoral fellows abroad. We reached out to them through our social network within the physics community and by using the snowball methodology. Most interviews were conducted online (using Skype) while the scientists were abroad conducting their research. Most interviewees were in their mid-thirties, all of them were in a relationship, and eleven of them had children. The number of children ranged between one and four, with two being the most common. The majority were admitted to postdoctoral studies in leading institutions in the USA and Europe. Since we followed their career in the years following this research, we note that the postdoctoral duration for most of them was four years.

The aim of the interviews was to understand the individual and institutional factors impacting their career decisions, whether to pursue an academic career in physics or to leave academia and take a different career path. We listened to their description of their academic path, their choices, and their ability to create the future they desire. 
All interviews with Ph.D. students and postdoctoral fellows were recorded, transcribed, and thematically analyzed using, in the first stage, the ATLAS.ti software and, in the second stage, a qualitative research analysis based on "grounded theory" [70].

\section{Quantitative-data collection}

The second phase of the research included quantitativedata collection. To have broader representative data covering all physics graduate students, male and female, we conducted a nationwide survey.

The survey questionnaire was compiled by the research team in consultation with researchers at the American Institute of Physics (AIP), which has been researching student attitudes toward physics for a decade. The research questionnaire that was formulated is partly based on the tools developed at AIP for research in the field but adapted to the Israeli context and to the research questions that interested us (see, for example, Ref. [76]). The questionnaire included 106 questions, six of which were open ended. The topics included the students' sociodemographic background, academic study track, attitudes regarding the academic environment, success indicators, the combination of family and studies, future employment expectations and intentions, the desire for an academic career, considerations in favor of and against postdoctoral studies, and aspects of discrimination and sexual harassment during the academic studies. Some findings of the survey are beyond the scope of this paper and are reported elsewhere [77].

Physics graduate studies are only possible at a few universities in Israel. Therefore, to conduct this research, we reached out to the Israeli Physical Society (IPS) for partnership and support. Through the IPS, we were able to reach the six physics faculties in the Israeli universities with a Ph.D. program in physics: Bar-Ilan University, BenGurion University, Hebrew University, the Technion, Tel Aviv University, and the Weizmann Institute of Science. Shouldered by the IPS, we asked the six physics deans for their help in distributing the survey, all of whom forwarded the survey request to their Ph.D. physics students. The deans also shared with the research team their data regarding the number of active students by gender. The data collected gave us the number of physics Ph.D. students in Israel by gender: of a total of $N=404$ students, 64 were women and 340 were men (in 2019).

To enhance the response rate, we promised all students full anonymity, distributed the survey through the faculty mailing lists, and reached out to students to encourage them to answer the questionnaire. As an extra incentive, we gave all participants a $\$ 15$ card to buy books. We received a remarkably high response rate of $66 \%$ of the overall population of students in the country $(267 / 404)$, with $94 \%$ of the women responding $(60 / 64)$ and $61 \%$ of the men $(207 / 340)$. We received answers from students in all
TABLE I. Physics Ph.D. students in Israel: the overall population and the number of respondents by institution.

\begin{tabular}{lccc}
\hline \hline Institution & Students & Respondents & Response rate \\
\hline Weizmann Institute & 109 & 71 & $65 \%$ \\
Bar-Ilan University & 67 & 50 & $74 \%$ \\
Hebrew University & 65 & 40 & $62 \%$ \\
The Technion & 65 & 39 & $60 \%$ \\
Tel Aviv University & 64 & 39 & $60 \%$ \\
Ben-Gurion University & 34 & 28 & $82 \%$ \\
Total & 404 & 267 & $66 \%$ \\
\hline \hline
\end{tabular}

six universities. Table I shows the population size and response rate by institution.

The maximum error for the entire population is $3.6 \%$, or $3.2 \%$ for women and $4.3 \%$ for men. Because of the representation of women in the sample, the total data of the students were weighted by gender. Given the small populations, the data were analyzed by using a proportion of variance analysis.

\section{FINDINGS}

\section{A. The postdoc as a "deal"}

Exploring student expectations of an academic career illustrates their image of the field. In our nationwide survey, we asked all Ph.D. students that stated that they would pursue an academic career (143/248) the following open question: "If you are interested in an academic career, please elaborate why?" Their answers were somewhat surprising. We found that love for physics and a deep interest in this field were the most common answers (66) (inter alia, loves research, loves exploring, loves basic research, this is my dream, it fits my character). The next most common answer (33) was academic freedom (the ability to conduct my own research, independence, no bosses or customers). The third most common answer (21) was related to the work conditions (favorable conditions, tenure, job security, prestige, social status, and leadership capacity).

All three reasons were also raised by the interviewees. We thus conclude that the main benefits of the academic career deal are the ability to engage in scientific research in a fascinating field, intellectual freedom to explore and be creative, independence in choosing what and how to do research, freedom from bosses and clients, and working conditions that guarantee employment stability and (reasonable) economic well being. The deal does not include quick enrichment but does include the prospect of groundbreaking scientific discoveries (and the concomitant worldwide fame), as well as the prestige that comes with being part of the exclusive club of the intellectual elite.

In light of these career benefits, we found that, at the crossroads of pursuing a postdoctoral position, the academic career is considered as a deal with three main 
components: personal-marital, professional-occupational, and financial. Young women realistically examine the components of this deal: what it offers them and what prices they have to pay. Although a decision is made based on these considerations, this does not imply that the considerations are all "rational" or "objective." Undoubtedly, the decision involves feelings and thoughts, realistic and unrealistic expectations, perceptions of academic institutions and the labor market, and aspirations for a professional and personal future. However, the bottom line is that all the above are merged into one informed decision of whether to go abroad for a postdoc as a necessary step for an academic position, or to quit the academic race at the current stage.

Embarking on a postdoctoral career is a significant and even dramatic step in the lives of young women (and men) and requires the will to make significant changes in many aspects of their life for a significant period of time. To obtain a tenure-track position in physics, two postdoctoral periods are often required, i.e., a cumulative period of about four years abroad. Therefore, it brings with it personal, family, professional, and financial considerations for both women and men and occurs under conditions of uncertainty and job insecurity. Women explore all of these aspects when they examine the option of a postdoc.

On the personal and family level, relocation to a foreign country is required, which includes in many cases the need to integrate children into new schools or kindergartens while learning a new language and integrating into a new social and cultural environment as well.

On the professional level, the candidate must find an academic mentor and an institution willing to host her for the postdoctoral period. This task requires talent, selfmarketing skills, a willingness to travel abroad, and an effort to become acquainted with suitable scientists and institutions. During the postdoctoral period, the candidate is required to prove herself again, to publish, to make a good impression on the relevant professional community, and to prove her capability as an independent scientist. After all these efforts, the postdoctoral researcher is not guaranteed an academic job because competition for such jobs is high, so her chances in this respect are unknown.

On the financial level, there is the concern for making a living. Typical scholarships during the postdoctoral period pay significantly less than the average wage of a physicist in the labor market. In addition, such scholarships do not include social benefits and the accrual of future rights, such as a pension or an education fund. Most scholarships are designed to allow a single person to live a modestly and usually do not suffice for a family. The costs of living abroad for a family with young children may be significantly higher than the average postdoctoral scholarship, which means that they have to fund postdoctoral studies through savings or family support, and this in a time of their lives when they are expected to be financially independent.
Moreover, relocation abroad may impair the spouse's income, employment continuum, and skills. For some professions, it is hard to find a parallel job abroad (for example, lawyers or military officers), and, in some cases, immigration-related restrictions do not allow the spouse to work.

All of these components are considered by the women and their spouses when pondering the decision of whether to go abroad for postdoctoral studies.

\section{B. Gendered aspects of the deal}

Women and men both examine the terms of the deal at a similar stage of their lives. It is clear that, for women, the gendered power structure creates different expectations and extra hurdles, which make their decision to undertake a postdoc more challenging.

The gendered power structure influences women's academic careers in physics in numerous ways. First, women face unequal competition in physics as a masculine field. Second, couples tend to prioritize the man's career over the woman's career. Third, the postdoctoral career path is socially perceived as a disruption of the gender order. Women justify this non-normative path by demanding of themselves exceptionally high standards of academic excellence. We claim that these standards of excellence operate as a hidden component within the gender regime that justifies the decision of women to do a postdoc.

\section{Unequal competition in physics as a masculine field}

As discussed in Sec. II B, physics is a masculine field, characterized by the supremacy of a white male majority, with a masculine culture and a masculine public image of the field. Thirty years after Traweek's work [24], the field of physics remains masculine and highly competitive in many western countries, including Israel. The gendered labor market in the physics field is clearly reflected in both our survey findings and the interviews. Over the last decade, females have accounted for only $16 \%-17 \%$ of the B.Sc., M.Sc., and Ph.D. physics students in Israel, and there is no sign that these numbers will increase. At the faculty level nationwide, females constitute only $6 \%$ of the overall staff in all physics faculties [4].

The marginal position of women in physics is evident not only quantitatively but also qualitatively (see the experiences of women in Table II). Most female Ph.D. students reported having experienced gender-based discrimination during their studies compared with only a small minority of men. Moreover, one in every five women reported being sexually harassed during their studies compared with one in forty among men. Of these women, half were harassed more than once, and only a minority of victims reported it to official entities. Similar findings in this regard were reported in Ref. [78] based on interviews with 21 women in graduate physics and astronomy programs (for a related study, see Ref. [79]). 
TABLE II. Results of survey on the issues of gender-based discrimination and sexual harassment.

\begin{tabular}{lllll}
\hline \hline & \multicolumn{2}{c}{ Female } & Male & \\
\cline { 2 - 3 } Topic & Yes/Total $(\%)$ & Yes/Total $(\%)$ & $P$ \\
\hline Have you experienced gender-based discrimination? & $34 / 54(63 \%)$ & $5 / 167(3 \%)$ & $<0.01$ \\
Have you been sexually harassed during your studies? & $13 / 59(22 \%)$ & $5 / 204(2.5 \%)$ & $<0.01$ \\
\hline \hline
\end{tabular}

As found from the interviews, the fact that women are different in the male-centric culture of physics plays against them, and the disadvantage becomes more prominent when they become parents. While women are expected to be the main caregivers, their male colleagues are expected to follow their career as they had done before becoming parents. Timing works to the detriment of women because, although they need flexibility to raise young children, they have to prove themselves to a highly demanding system that does not stop for a moment [80], a system in which there is no such thing as a "good" time to have children.

Although many of the women interviewed said that they strive to implement an egalitarian model of childcare at home, most of them also report spending longer hours in childcare and child-related work compared with their partners, and that this comes at the expense of their studies.

These findings are supported by the survey data that indicate that, despite the prominent presence of an egalitarian ideology among physics-student families, expressed by the desire of both the women and the men for an equal distribution of roles, the women evidently carry a greater burden of family work. First, they take a longer maternity leave, which impedes their studies: Most women take a maternity leave of four months or more, compared with a very short parental leave taken by male students. See Table III for the full survey results. As apparent from the interviews, women must also go through the pre-birth period during which many women must undergo various examinations and sometimes require medical care and observation, which require time and a lot of medical attention (a reality that may also repeat itself after the maternity leave).

Second, women reported more than their male colleagues that, due to parenthood, they adopted a more flexible work schedule and learned to be more productive in their studies. See Table IV for the full survey results.

TABLE III. Results of survey for the following question: What is the duration of the maternity leave you took after the birth of your last child? $\chi^{2}=92.67, P<0.00001$.

\begin{tabular}{lcc}
\hline \hline & Female $n(\%)$ & Male $n(\%)$ \\
\cline { 2 - 3 } Duration & $(n=21)$ & $(n=93)$ \\
\hline$\leq$ week & $1(5 \%)$ & $61(66 \%)$ \\
Week-month & $0(0 \%)$ & $28(30 \%)$ \\
$1-3$ months & $5(24 \%)$ & $4(4 \%)$ \\
$\geq 4$ months & $15(71 \%)$ & $0(0 \%)$ \\
\hline \hline
\end{tabular}

Third, examination of the role-distribution structure in these families indicates that, although the fathers are engaged in childcare, gender inequality remains (see Table V). All the women reported that they are responsible for taking care of their children's needs, either as the primary caretaker or by sharing childcare equally with their spouse. In contrast, while the majority of men reported that they share the childcare responsibility with the spouses, more than a quarter reported that most childcare responsibilities fall on the shoulders of their spouses, and only a small minority reported bearing most of the childcare responsibility.

Moreover, although most women and men reported sharing household chores, none of the women were free from this burden (the remaining 33\% of women reported that the household burden mostly lies on their shoulders), whereas men either share the burden with their spouses or it falls mainly on their spouses. See Table V for the detailed results.

These findings are not surprising: they have been manifested in studies on housework and childcare in western democracies for decades. According to the American timeuse survey, women spend an average of $2 \mathrm{~h}, 15 \mathrm{~min}$ a day on housework, whereas men spend $1 \mathrm{~h}, 25$ min [81]. Women continue to take the primary responsibility for home and family even in some of the most gender-equal countries [82].

This gendered role division at home is reflected in academia by the greater presence of men than women at physics labs and offices in terms of time allocation. Most male physicists (even if they honestly believe in gender equality) do not practice parenthood in the same way as women. Although most male Ph.D. students declared that parenthood affected their studies, parenthood is not as significant a variable in their lives as employment, because

TABLE IV. Results of survey for the following question: How did your course of study change as a parent?

\begin{tabular}{lrrr}
\hline \hline & Female $n(\%)$ & Male $n(\%)$ & \\
\cline { 2 - 3 } & $(n=18)$ & $(n=89)$ & $P$ \\
\hline Reduced time for study & $15(83 \%)$ & $64(73 \%)$ & \\
More flexible schedule & $12(67 \%)$ & $42(48 \%)$ & $<0.05$ \\
More efficiency & $8(44 \%)$ & $24(27 \%)$ & \\
Reduced pace of studies & $7(39 \%)$ & $30(34 \%)$ & \\
No change & $1(6 \%)$ & $12(14 \%)$ & \\
\hline \hline
\end{tabular}


TABLE V. Results of survey on the issues of childcare and household.

\begin{tabular}{|c|c|c|c|c|c|c|c|}
\hline \multirow[b]{2}{*}{ Topic } & \multicolumn{3}{|c|}{ Female $n(\%)$} & \multicolumn{3}{|c|}{ Male $n(\%)$} & \multirow[b]{2}{*}{$P$} \\
\hline & Student & Equally & Spouse & Student & Equally & Spouse & \\
\hline On whom lies the main responsibility of childcare? & $12(57 \%)$ & $9(43 \%)$ & $0(0 \%)$ & $5(5 \%)$ & $61(66 \%)$ & $26(28 \%)$ & $<0.01$ \\
\hline On whom lies the main responsibility of the household? & $7(33 \%)$ & $14(67 \%)$ & $0(0 \%)$ & $11(12 \%)$ & $61(64 \%)$ & $23(24 \%)$ & $<0.01$ \\
\hline
\end{tabular}

they follow the social expectation that the family will be pushed aside by their career demands. At the same time, the common expectation of Israeli women is to be both dedicated mothers and career women.

The interviews show that women's greater commitment to family makes it harder for them to succeed in their studies within a male-dominated culture. Young women report being discriminated against based on the normative assumption that mothers are less competent and committed than other types of workers, as was documented in previous research addressing the "motherhood penalty" phenomenon [83].

T., a mother of a two-year-old girl who was pregnant at the time of the interview, told us about the difficulty of combining studies with motherhood. T. aspires to an academic career but, at the same time, she gives high priority to her family. She tries to live up to the social expectation of "doing both." She finds that this situation puts her at a disadvantage in her daily competition with her male counterparts. Her commitment to family, or what she calls "this problem," is her problem, and not a problem of her colleagues, all of them male and free from having to live up to the expectation of being the main caregivers for their children. T. describes it in a tone of acceptance but also criticizes it:

"My family, my husband, my marriage, and my children are very important for me; they are very high in my priorities .... I feel the gender differences (compared to male colleagues) mainly since I have much less time to work than my friends from the lab, and it becomes a big gap ... it's like you are competing against those to whom you compare yourself, all the time .... It's hard to combine motherhood with anything that is career-related, not only in academia, but the competition is a competition with men who don't have this problem."

As a young mother, the difficulty of combining career and motherhood requirements becomes clear to T. Taking care of her two-year-old daughter takes precious time and hinders her ability to successfully compete with other students and her lab colleagues, whose time is at their disposal and are less challenged by family demands.

The women's experience is structured within a gendered labor market, where men and women have to live up to the same expectations at work, in the public sphere, but have different expectations in the private sphere. Women's understanding that physics as a field is gendered, that the competition in which they are competing and will be required to compete is unequal, and that their challenge is to be both a mother and a career woman, leads some of them to quit the academic career race. Those who stay in the race understand that they must succeed in these gendered conditions, competing from an unequal starting point with those who are free from the "second shift" at home.

\section{Prioritizing family and husband's career}

In comparison with other Western democracies, students in Israel start academic studies relatively late and marry relatively young. Therefore, the family situation of Ph.D. students in Israel has unique characteristics.

Based on our survey of Ph.D. students, male and female Ph.D. students in physics are in their early thirties. The average age is 29.7 among women and 31.8 among men. Most women and men are already married or in a relationship, and more than a third of them already have children. Moreover, about $23 \%$ of male and $17 \%$ of female Ph.D. students have two children or more. See Table VI for details.

This picture is clearly reflected in the interviews. Most of the Ph.D. students we interviewed (21 out of 25) already had spouses, half of them (12) were already mothers of young children at the time of the interview, and the single women declared their desire to become mothers in the coming years.

The majority of the spouses of the female students interviewed were working in STEM fields or were graduate students in STEM fields. Most of the female students described their spouses as mostly supportive in their career aspirations and decisions, wanting and willing to help them succeed. In the survey, many students described their spouse as one of the factors for their own success [89\% of women (42/47) and 80\% of men (124/155), $p<0.01]$. However, the interviews clearly indicate that, once a spouse enters the picture, career and family considerations become

TABLE VI. Family status of survey respondents.

\begin{tabular}{lcr}
\hline \hline & Female $n(\%)$ & Male $n(\%)$ \\
\cline { 2 - 3 } & $(n=58)$ & $(n=189)$ \\
\hline Married & $37(64 \%)$ & $132(70 \%)$ \\
Children & $20(34 \%)$ & $77(41 \%)$ \\
$\geq 2$ children & $10(17 \%)$ & $44(23 \%)$ \\
\hline \hline
\end{tabular}


TABLE VII. Survey results on the following question: If you are considering going abroad for a postdoc, how central is this consideration in your decision?

\begin{tabular}{lcrc}
\hline \hline & Female $n(\%)$ & Male $n(\%)$ & \\
\cline { 2 - 4 } & $(n=41)$ & $(n=127)$ & $P$ \\
\hline Spouse's employment possibilities & $39(95 \%)$ & $114(89 \%)$ & \\
Spouse and family relocation & $38(93 \%)$ & $107(84 \%)$ & $<0.05$ \\
Putting the spouse's career on hold & $37(90 \%)$ & $99(78 \%)$ & $<0.05$ \\
Funding & $37(90 \%)$ & $126(99 \%)$ & $<0.05$ \\
\hline \hline
\end{tabular}

intertwined and therefore more complex. Career becomes "spousal" in the sense that a decision made with regard to the man's career affects the woman's career, and vice versa. The couple must consider the impact of their choices on the entire family.

The interviews with female Ph.D. students and female postdocs showed without a doubt that women give significant weight to the implications on their spouse's career of doing a postdoc. Women are preoccupied with the questions: Will my spouse be able to find a job or a postdoc abroad (in view of language- and visa-related barriers)? Will he be able to find work abroad that fits his skills and ambitions (depending on his professional characteristics, job availability, ability to adapt to a different job market, etc.)?

A clear example of a spousal career and interrelated career considerations emerges from the story of S., married with two toddlers. S. and her husband are both Ph.D. students at the last stage of their studies. S. found it difficult to separate her career aspirations from her partner's aspirations, which she presented as interdependent. The interviewer tried to refine the differences and understand what she wanted:

Q: 'I' $m$ trying to understand how you see your career, if you didn't have any limitations, where would you like to see yourself?"

A: "Now, it seems that my doctorate is going to be more or less successful, and I'll have good results, so yes, I would like to continue in academia and do a postdoc, and I know that there are some institutions in Europe ... they are looking for people (in our field) and we can both get work there, some sort of a postdoc, so that could be nice. But now it comes to my husband and if he finds a place that he will really love, and there won't be a place for two people there, I'll go look for a job in high-tech or something else, and that would also be perfectly fine, and if I won't find a job in high-tech, I will be a teacher and it will also be fun.... It won't be as interesting as research, but it's a job."

S. clearly subordinates her desire to undertake a postdoc in physics to that of her spouse; his career is clearly given priority within the spousal relationship, although her Ph.D. was good, and she recently won an award for excellence.

In another case, the counterweight to a postdoc was the spouse's desire to stay in Israel. B.G. is freshly married and pregnant with her first child. She told us that her spouse supports her but at the same time does not want to leave Israel and is very connected to his country and his family. B.G. eventually decided to leave academia. It is impossible to determine if it was her spouse who led to the decision against a postdoc, but it was clear that his will carried significant weight in her decision.

The survey results reinforce the findings that emerged from the interviews. While both men and women reported that their spouse's employment considerations play a key role in their decision of whether to go for a postdoc, women gave more weight to this issue. Similarly, a higher percentage of the women indicated that their spouse's ability to find a job abroad was a key consideration, and a higher percentage of women noted as a key consideration the difficulties involved in relocating abroad with the spouse and family. See Table VII for the full survey results.

Thus, it appears that, even if the male spouse is supportive and willing to follow his partner abroad, women give greater weight to the career, desires, and preferences of their spouses. This reflects, inter alia, the gendered power structure that exists within society and in the job market.

The priority and precedence given to the man's career in many families could be based on the understanding of their better chances for higher wages and promotion (on average) in the job market. It was surprising to find that, even at this early stage when most students live on a modest subsistence scholarship, financial gaps in income already favor the men. The majority of female Ph.D. students indicated that their spouse's income from school or work exceeded their own income, compared with a minority of male Ph.D. students. See Table VIII for the detailed results.

TABLE VIII. Results for the following question: Compare your spouse income to yours. $\chi^{2}=24.48, P<0.00001$.

\begin{tabular}{lcc}
\hline \hline & Female $n(\%)$ & Male $n(\%)$ \\
\cline { 2 - 3 } & $(n=37)$ & $(n=134)$ \\
\hline Higher than mine & $25(67 \%)$ & $37(28 \%)$ \\
Similar to mine & $8(22 \%)$ & $27(20 \%)$ \\
Lower than mine & $4(11 \%)$ & $61(46 \%)$ \\
Has no income & $0(0 \%)$ & $9(6 \%)$ \\
\hline \hline
\end{tabular}




\section{Postdoctoral career path as a disruption of the gender order}

In the Israeli context, it is essentially required to undertake postdoctoral studies abroad, which means that the student must leave the country for a prolonged period of professional research and development. (The requirement is not formal, but the probability of getting an academic position after a postdoc in Israel is much lower.) Although the common view in contemporary educated circles is that the job market is open and equal for women, the interviews reveal a much more conservative view. The social and family environment clearly perceives postdoctoral studies as an ambitious and non-normative path for women. It is common for women to follow their spouses for a period of work or studies abroad, but the opposite model is still considered non-normative and is perceived as "feminist" and challenging the common social order, in which the male career is the lead.

Consider more examples: Ts. was about to embark on a prestigious postdoc in the USA with her husband. She described the postdoctoral path as non-normative for a woman, which is why it had to be negotiated with her spouse and be justified against the family system:

"I think a postdoc abroad takes a heavy toll. Usually, the husband is older and has a job and does not want to leave. The easy cases are when the husband also goes for a postdoc, or can work abroad and, in such a case, he wants to leave. Even if the husband is supportive, the extended family wrinkle up their noses and put pressure on me (not to go on a postdoc abroad). If it were possible to do a postdoc in Israel, it would be much easier for women."

M., a single Ph.D. student, believes that women are less likely to go for a postdoc because it is a deviation from the conventional structure of gendered power relations. In the accepted social order, a man's career is the significant one, and not the other way around:

"I think that the cultural perception, at least in Israel, is that the woman will follow the man, i.e., if the man has to relocate due to work or studies, it is perceived as more natural for the woman to follow him."

M. says the postdoc issue came up in her previous relationship, and although her former boyfriend's attitude regarding this issue was positive, his social environment was against this move and regarded it as non-normative. The idea of him, a man, relocating abroad for the benefit of his girlfriend's career, was met with criticism and astonishment by his colleagues.

The power structure in the job market that emerges in interviews reflects the patriarchal structure of society and power relations within the family. When a man follows his wife abroad, it disrupts the gender order. The priority given within the family to the male's career restricts women from embarking on a postdoc and limits their choice of academic career.

This gendered power structure is so deeply rooted that it even affects single women with no children. Three single
Israeli female Ph.D. students whom we interviewed claim that they refrained from embarking on postdoctoral studies, inter alia, due to the concern that they may impair their chances to get married in the future or that it may limit a future (spouse's) career.

\section{Self-expectations for excellence: A hidden component in the gender power structure}

As found in previous studies, women must demonstrate greater abilities than men to be recognized as equally good. For women to be considered good and worthy of employment and promotion in male-dominated disciplines, they must be better than their male peers $[84,85]$.

In a gendered workforce, when women compete over an academic career in a masculine field, having to overcome gender discrimination and the motherhood penalty, prioritizing their husband's career at home, and taking a greater share of the childcare, what justifies their decision to go on a postdoc abroad or to embrace the academic deal?

Based on our research results, we claim that, to justify this deviation from the "gender order," women push themselves to excel. Excellence was singled out as a justification that allows deviation from the norm and disruption of the gender order. Many women stated that it is considered obvious that, when a man goes abroad for a postdoc, his wife goes with him, even if it requires her to give up her career. In contrast, for a woman to embark on a postdoc with her partner joining her, special conditions must be met. One of the unspoken conditions, mentioned repeatedly during the interviews, is being an excellent student. This is how B.G., married and pregnant, explains why she decided to leave academia for a job in the industry after completing her Ph.D.:

"Women are also affected by their partner, not that men are not, but to a certain extent, when a man thinks about going for a postdoc, his wife is excited to follow him ... it's an adventure. (On the contrary,) a woman waits to hear the man's opinion, and if he says no, then there should be a really good reason, for example, when (your) doctorate is brilliant and the supervisor wants you to travel for postdoc ... then, maybe then."

To deviate from the norm, the woman must be excellent. It is not enough for her to be a good or even very good student, and she probably cannot afford a postdoc if she is an average student. The excellence must be reflected in numerous aspects that are interconnected: her academic achievements, her supervisor's evaluation of her, the professional group perception of her academic potential, and her ability to receive a postdoctoral offer from a top institute.

Excellence has two functions: one in the public sphere and one in the private sphere. In the public sphere, excellence allows the student to feel worthy to face professional competition from their male colleagues. In the private sphere, it justifies (to the spouses and to the 
women themselves) their choice of a non-normative career path for a woman, which includes going abroad for a postdoc and subordinating the family to her career needs.

A clear example of excellence as a justification for disruption of the gender order comes out from the story of A., recently married with a baby. A. said she had already decided when she started her Ph.D. that she would not pursue a postdoc in a place that is "not good." She says that, in the beginning of their relationship, she and her husband agreed that she would pursue postdoctoral studies if she were accepted into a prestigious institution. In return, he promised that he would be willing to leave his job to support her career. The following is her answer to the question of whether she would like to embark on postdoctoral studies abroad:

"Yes, very much! But it is contingent upon me getting a good postdoc! I mean, not a postdoc from the University of Nowhere, I don't know, something like that, it should be a good postdoc! Because basically, my husband will come with me and will have to take a leave without pay, which is also not so trivial at work .... I won't drag the entire family if it's a postdoc that will get me nowhere, you know, it should be a good and lucrative postdoc, so I would have some motivation to return to Israel. I really want to be in academia, and I think that science is just the best thing there is, in my opinion, and it's something I want to do all my life."

Another example comes from the story of V., a married mother of three, who is about to graduate. She shares her doubts about the future and claims her spouse supports her postdoc aspirations; however, if they relocate, he would have to give up a job that is a significant part of his life. Therefore, for V., going for a postdoc costs a high price in terms of her partner's career. After some deliberation, V. decided to do her first postdoc in Israel. Only if it is successful will she go abroad for another postdoc.

An academic career is viewed by the social and family environment not only as a highly demanding and competitive path but also as a masculine, non-normative path for women. Women in physics understand that they must compete under unequal conditions of a gendered labor market, and that they must excel to be perceived as equal. Under these conditions, excellence operates as a hidden component within the unseen gender regime that justifies and allows deviation from the gender order by going for a postdoc abroad and prioritizing a woman's career over her husband's career.

Motivation is all that is needed for a married man to go for a postdoc abroad, whereas motivation alone is insufficient for women to attempt the same. Married women need a very good justification for their non-normative career choice and for their husbands to follow them. This might be one of the dominant reasons for the low number of women pursuing an academic career in physics and the gender imbalance in the academic staff of physics departments.

\section{SUMMARY AND DISCUSSION}

This study uses a nationwide survey and in-depth interviews with female physics students as a robust empirical basis to explore the decision-making process of women in physics at the crossroad of an academic career. We study career decisions in physics as a multilayered and multidimensional process. The theoretical novelty that we propose is to view this process as a deal that involves contextual, organizational, and individual variables and their intersection. Young women examine the components of this deal: what it offers them and what prices they will have to pay, but their decision is made within a gendered power structure. Studying both context factors and agency, we find that an academic career in physics offers a deal with three main components: personal-marital, professionaloccupational, and financial. Young women realistically examine the terms of this deal, what it offers them, and what prices they will have to pay. Their decision is made in accordance with these considerations, but, contrary to men, women must operate within a gender power structure that affects their decisions in a different way.

While both women and men consider the terms of the deal in a similar stage of their lives, the gendered power structure creates different expectations among the women and extra hurdles, which makes the decision to pursue an academic career and to undertake a postdoc more challenging. Our findings reveal the multiple and hidden ways in which gender operates as a power structure within society, in the labor market within physics as an academic field, and in the family within the private sphere, putting up a considerable barrier to women's academic careers.

This latent power structure influences women's decision making and experiences in several ways. In the academic field, it produces unequal competition in a male-dominated playground, where women struggle to succeed as physicists and as mothers, but are viewed as less devoted workers because of their parental commitment. Within the private sphere, women carry a greater share of the childcare and family work and, moreover, give priority and precedence to their husband's career and preferences. In the social sphere, choosing a demanding academic career is seen as a nonnormative trajectory for women and as disrupting the gender order.

Women justify this non-normative path by raising their self-expectations for excellence. They feel that they must excel in their research and exhibit exceptional achievements. We claim that excellence operates as a hidden mechanism within the gender regime that can not only justify a woman's decision to undertake a postdoc but also operate as an exclusionary mechanism that prevents many talented young women from choosing an academic career in physics. We should thus stop thinking about women giving up academic careers ("the leaky pipeline" discussion; see, e.g., Refs. $[86,87])$ but rather think about choosing career paths that align better with the gender regime within diverse social and cultural contexts. 
Our acquaintance with the physics culture in the USA and in Europe and our close collaboration with the community researching gender in physics in the European academy (particularly the GENERA network [88]) lead us to believe that many of the main findings of this research and our accompanying theoretical arguments apply not only to physics in Israel but also more universally, at least in the context of physics in western countries. The unique features of Israeli society are helpful in amplifying some factors that affect the decisions involved in accepting the deal offered by a career in physics. Further research is needed, however, to support these findings and to explore hidden barriers that hinder the integration of women into academic careers in physics and in other scientific disciplines where they still constitute a token minority.

If we want academia to be more gender balanced so that women are no longer a token minority, we should tackle the many obstacles women face, both in physics as a field and within the family circle. We should make physics more appealing to women, knowing that their choices are made within a gendered structure and that the academic path is more demanding for them. If academia does not act in this direction, it will lose talented females to global technology companies, which in recent years have made intensive efforts to change the gender balance among their employees and integrate more women into diverse work teams.

\section{ACKNOWLEDGMENTS}

We thank Sharon Diamant-Pick for her help in conducting the survey and in analyzing the interviews. Y. N. is supported by the Amos de-Shalit chair of theoretical physics. This research is supported by grants from the Israeli Ministry of Science and Technology, from the Estate of Rene Lustig, and from the Estate of Jacquelin Eckhous.
[1] A. M. Porter and R. Ivie, Women in Physics and Astronomy, 2019, Technical Report, (AIP Statistical Research Center, College Park, MD, 2019).

[2] J. Blue, A. L. Traxler, and X. Cid, Gender matters, Phys. Today 71, No. 3, 40 (2018).

[3] Women in Physics: 6th IUPAP International Conference on Women in Physics, edited by C. Singh, G. Cochran, and N. Wilkin, AIP Conference Proceedings (2019), Vol. 2019, https://printorders.aip.org/proceedings/2109.

[4] M. Eran-Jona and Y. Nir, Women in physics in Israel: An overview, in Women in Physics, in 6th IUPAP International Conference on Women in Physics, AIP Conference Proceedings (2019), Vol. 2109, p. 050022, https://aip.scitation.org/doi/pdf/10.1063/1.5110096.

[5] J. Van Maanen and E. H. Schein, Toward a theory of organizational socialization, in Research in Organizational Behavior, edited by B. M. Staw (JAI Press, Greenwich, Conn., 1979), Vol. 1.

[6] K. Chudzikowski and W. Mayrhofer, In search of the blue flower? Grand social theories and career research: The case of Bourdieu's theory of practice, Human Relations 64, 19 (2010).

[7] R. W. Connell, Gender and Power: Society, the Person and Sexual Politics (Stanford University Press, Palo Alto, CA, 1987).

[8] N. Hartsock, Rethinking modernism: Minority vs. majority theories, Cultural Critique 7, 187 (1987).

[9] A. Komter, Gender power and feminist theory, in The Gender of Power, edited by K. Davis, M. Leijenaar, and J. Oldersma (Sage Publications, London, 1991).

[10] J. W. Scott, Gender: A useful category of historical analysis, Am. Historical Rev. 91, 1053 (1986).

[11] D. L. Sheppard, Organization power and sexuality: The image and self-image of women managers, in The
Sexuality of Organization, edited by J. Hearn, D. L. Sheppard, P. Tancred-Sheriff, and G. Burrell (Sage Publications, London, 1989).

[12] R. M. Kanter, Men and Women of the Corporation (Basic Books, New York, 1977).

[13] J. Acker, Hierarchies, jobs, bodies: A theory of gendered organizations, Gender Soc. 4, 139 (1990).

[14] R. W. Connell, The State, gender, and sexual politics: Theory and appraisal, Theory Soc. 19, 507 (1990).

[15] B. F. Reskin and P. A. Roos, Status hierarchies and sex segregation, in Ingredients for Women's Employment Policy, edited by C. Bose and G. Spitze (SUNY Press, Albany, 1987).

[16] R. Connell, New maps of struggle for gender justice: Rethinking feminist research on organizations and work, Gender Work Org. 26, 54 (2019).

[17] J. Acker, Inequality regimes: Gender, class, and race in organizations, Gender Soc. 20, 441 (2006).

[18] E. Holvino, Intersections: The simultaneity of race, gender and class in organization studies, Gender Work Org. 17, 248 (2010).

[19] N. Toren, Mizrahi women in academia: Gender, ethnicity and social status, in Gender and Ethnicity in the Israeli Academy (in Hebrew), edited by R. HerzLazarowitz and I. Oplatka (Pardes Publications, Haifa, Israel, 2009).

[20] M. Eran-Jona and G. Perez, What can the "Start-Up Nation" do to enhance diversity in physics?, in Weizmann Institute of Science Research Report (Weizmann Institute of Science, Rehovot, Israel, 2020).

[21] A. J. Gonsalves, A. Danielsson, and H. Pettersson, Masculinities and experimental practices in physics: The view from three case studies, Phys. Rev. Phys. Educ. Res. 12, 020120 (2016). 
[22] P. Bourdieu, Outline of a Theory of Practice (Cambridge University Press, Cambridge, MA, 1977).

[23] P. Bourdieu, The forms of capital, in Handbook of Theory and Research for the Sociology of Education, edited by J. G. Richardson (Greenwood, New York, 1986).

[24] S. Traweek, Beamtimes and Lifetimes: The World of High Energy Physicists (Harvard University Press, Cambridge, MA, 1988).

[25] K. L. Lewis, J. G. Stout, S. J. Pollock, N. D. Finkelstein, and T. A. Ito, Fitting in or opting out: A review of key social-psychological factors influencing a sense of belonging for women in physics, Phys. Rev. Phys. Educ. Res. 12, 020110 (2016).

[26] B. Bagilhole and J. Goode, The contradiction of the myth of individual merit, and the reality of a patriarchal support system in academic careers: A feminist investigation, Eur. J. Women's Studies 8, 161 (2001).

[27] L. Bailyn, Academic careers and gender equity: Lessons learned from MIT, Gender Work Org. 10, 137 (2003).

[28] Y. Benschop and M. Brouns, Crumbling ivory towers: Academic organizing and its gender effects, Gender, Work Org. 10, 194 (2003).

[29] A. Gofen, Academic Career of Graduates with Excellent Grades in SET Fields 1995-2005, Research Report of the Federman School of Public Policy and Government (Hebrew University of Jerusalem, Jerusalem, 2011).

[30] M. Lamont and V. Molnar, The study of boundaries in the social sciences, Annu. Rev. Sociol. 28, 167 (2002).

[31] J. M. Gerson and K. Peiss, Boundaries, negotiation, consciousness: Reconceptualizing gender relations, Soc. Probl. 32, 317 (1985).

[32] C. F. Epstein, Border crossings: The constraints of time norms in transgressions of gender and professional roles, in Fighting for Time: Shifting Boundaries of Work and Social Life, edited by C. F. Epstein and A. L. Kalleberg (Russell Sage Foundation, New York, 2004).

[33] J. Gvozdanovic and K. Maes, Implicit bias in academia: A challenge to the meritocratic principle and to women's careers-And what to do about it?, LERU advice paper, 2018.

[34] D. Atewologun, T. Cornish, and F. Tresh, Unconscious Bias Training: An Assessment of the Evidence for Effectiveness (Equality and Human Rights Commission, Manchester, UK, 2018).

[35] A. A. Eaton, J. F. Saunders, R. K. Jacobson, and K. West, How gender and race streotypes impact the advancement of scholars in STEM: Professors' biased evaluations of physics and biology post-doctoral candidates, Sex Roles 82, 127 (2020).

[36] Sexual harassment of women: Climate, culture, and consequences in academic sciences, engineering, and medicine, edited by P. A. Johnson, S. E. Widnall, and F. F. Benya (National Academies Press, Washington, DC, 2018).

[37] S. Kulis, D. Sicotte, and S. Collins, More than a pipeline problem: Labor supply constraints and gender stratification across academic science disciplines, Research Higher Educ. 43, 657 (2002).

[38] From scarcity to visibility: Gender differences in the careers of doctoral scientists and engineers, edited by
J. S. Long (National Academies Press, Washington, DC, 2001).

[39] N. H. Wolfinger, M. A. Mason, and M. Goulden, Problems in the pipeline: Gender, marriage, and fertility in the ivory tower, J. Higher Educ. 79, 388 (2008).

[40] M. Goulden, K. Frasch, and M. A. Mason, Staying competitive: Patching America's leaky pipeline in the sciences, Berkeley Center on Health, Economy \& Family Security and the Center for American Progress Report (2009), https://www.americanprogress.org/issues/women/reports/ 2009/11/10/6979/staying-competitive/; Keeping women in the science pipeline, Ann. AAPSS 638, 141 (2011).

[41] R. Carmi et al., The team for examining the situation of women in the academic staff of high education institutesreport and recommendations (in Hebrew), Israeli Council for Higher Educ. (2011).

[42] J. P. Byrnes, D. C. Miller, and W. D. Schafer, Gender differences in risk taking: A meta-analysis, Psychol. Bull. 125, 367 (1999).

[43] R. W. Lent, S. D. Brown, and G. Hackett, Toward a unifying social cognitive theory of career and academic interest, choice, and performance, J. Vocat. Behav. 45, 79 (1994).

[44] A. M. Kanny, L. J. Sax, and T. A. Riggers-Piehl, Investigating forty years of STEM research: How explanations for the gender gap have evolved over time, J. Women Minorities Sci. Engin. 20, 127 (2014).

[45] M. M. Chemers, L.-t. Hu, and B. F. Garcia, Academic selfefficacy and first year college student performance and adjustment, J. Educ. Psychol. 93, 55 (2001).

[46] R. W. Lent, F. G. Lopez, and K. J. Bieschke, Mathematics self-efficacy: Sources and relation to science-based career choice, J. Counsel. Psychol. 38, 424 (1991).

[47] M. L. Grunert and G. M. Bodner, Finding fulfillment: Women's self-efficacy beliefs and career choices in chemistry, Chem. Educ. Res. Pract. 12, 420 (2011).

[48] N. A. Falk, P. J. Rottinghaus, T. N. Casanova, F. H. Borgen, and N.E. Betz, Expanding women's participation in STEM: insights from parallel measures of self-efficacy and interests, J. Career Assess. 25, 571 (2017).

[49] Y. Nir, M. Eran-Jona, and S. Diamant-Pick, Is mentoring in academia gender biased? Gender differences in the advisor's support of doctoral students in physics, Gender 8, 1 (2021) (in Hebrew).

[50] R. Ivie, S. White, and R. Y. Chu, Women's and men's career choices in astronomy and astrophysics, Phys. Rev. Phys. Educ. Res. 12, 020109 (2016).

[51] P. Hodkinson and A. C. Sparkes, Careership: A sociological theory of career decision making, Brit. J. Sociology Educ. 18, 29 (1997).

[52] M. W. Nielsen, Reasons for leaving the academy: A case study on the 'opt out' phenomenon among younger female researchers, Gender Work Org. 24, 134 (2016).

[53] K. Beddoes and A. Pawley, Different people have different priorities: Work-family balance, gender, and the discourse of choice, Studies Higher Educ. 39, 1573 (2014).

[54] P. Bourdieu, Distinction: A Social Critique of the Judgment of Taste (Harvard University Press, Cambridge, MA, 1984). 
[55] P. Bourdieu, Sociology in Question (Sage Publications, London, 1993).

[56] P. Bourdieu and J.-C. Passeron, Reproduction in Education, Society and Culture (Sage Publications, London, 1990).

[57] P. Bourdieu and L. J. D. Wacquant, An Invitation to Reflexive Sociology (The University of Chicago Press, Chicago, IL, 1992).

[58] R. Weitz, Women and their hair: Seeking power through resistance and accommodation, Gender Soc. 15, 667 (2001).

[59] G. Yair, A different reason: How Israeli scientists think about careers and family life, Israel Studies 25, 159 (2020).

[60] S. Fogiel-Bijaoui, Families in Israel: Between familism and postmodernism, in Sex, Gender and Politics, edited by D. Izraeli, A. Friedman, H. Dahan-Kalev, H. Naveh, S. Fogiel-Bijaoui, M. Hassan, and H. Herzog (Kav Adom, Hakibbutz Hameuchad, Tel Aviv, 1999) (In Hebrew).

[61] The Israeli Central Bureau of Statistics, Fertility rates of Jewish women and other in Israel by level of religiosity 1979-2017, Table No. 1, https://www.cbs.gov.il/EN/pages/ default.aspx (2020).

[62] A. Guy and A. Shnider, Old characteristics of gender discrimination in the new workforce structure, The Heth Academic Center for Research of Competition and Regulation publication (in Hebrew) (2019).

[63] O. Anabi, Fathers' involvement in the domestic arena and ideologies of masculinity in Israeli society, Ph.D. thesis, University of Bar-Ilan, Israel, 2019 (In Hebrew).

[64] A. Doucet, Parental responsibilities: Dilemmas of measurement and gender equality, J. Marriage Family 77, 224 (2015).

[65] S. S. Case and B. A. Richley, Gendered institutional research cultures in science: The post-doc transition for women scientists, Community Work Family 16, 327 (2013).

[66] N. Toren, Tradition and transition: Family change in Israel, Gender Issues 21, 60 (2003).

[67] S. Mizrahi Simon, Women in Israel: Central issues, the Knesset Research and Information Center report (in Hebrew) (The Knesset Research and Information Center, Jerusalem, 2015).

[68] R. Kark, Women in the land of milk, honey and high technology: The Israeli case, in Women and Minorities in Science, Technology, Engineering and Mathematics, edited by R. J. Burke and M. C. Mattis (Edward Elgar Publishing Limited, Cheltenham, UK, 2007).

[69] C. Glesne and A. Peshkin, Becoming Qualitative Researchers: An Introduction (Longman, New York, 1992).

[70] Collecting and Interpreting Qualitative Materials, edited by N. K. Denzin and Y.S. Lincoln (Sage Publications, Thousand Oaks, CA, 1998).
[71] R. B. Johnson, A. J. Onwuegbuzie, and L. A. Turner, Toward a definition of mixed methods research, J. Mixed Methods Res. 1, 112 (2007).

[72] S. Reinharz and L. Davidman, Feminist Methods in Social Research (Oxford University Press, New York, 1992).

[73] M. L. DeVault, Feminism and Social Research: Liberating Method (Temple University Press, Philadelphia, PA, 1999).

[74] Feminist Research Methodologies, edited by M. KrumerNevo, M. Lavie-Ajayi, and D. Hacker (Hakibutz Hameuchad Publications, Migdarim Series, Tel Aviv, 2014).

[75] Bar Ilan University, Ben Gurion University, Hebrew University, the Technion, Tel Aviv University, and Weizmann Institute.

[76] P. Mulvey and J. Pold, Physics doctorates: Skills used and satisfaction with employment, AIP report (American Institute of Physics, College Park, MD, 2020).

[77] M. Eran-Jona and Y. Nir, Ph.D. in physics as a hurdle race, and the "glass hurdles" for women, arXiv:2007.02251.

[78] R. S. Barthelemy, M. McCormick, and C. Henderson, Gender discrimination in physics and astronomy: Graduate student experiences of sexism amd gender microaggressions, Phys. Rev. Phys. Educ. Res. 12, 020119 (2016).

[79] L. M. Aycock, Z. Hazari, E. Brewe, K. B. H. Clancy, T. Hodapp, and R. M. Goertzen, Sexual harassment reported by undergraduate female physicists, Phys. Rev. Phys. Educ. Res. 15, 010121 (2019).

[80] S. J. Ceci and W. M. Williams, The Mathematics of Sex: How Biology and Society Conspire to Limit Talented Women and Girls (Oxford University Press, New York, 2010).

[81] U.S. Bureau of Labor Statistics, American Time Use Survey (ATUS), https://www.bls.gov/tus/.

[82] C. Seierstad and G. Kirton, Having it all? women in high commitment careers and work-life balance in Norway, Gender Work Org. 22, 390 (2015).

[83] S. Benard and S. J. Correll, Normative discrimination and the motherhood penalty, Gender Soc. 24, 616 (2010).

[84] M. E. Heilman and M. C. Haynes, Subjectivity in the appraisal process: A facilitator of gender bias in work settings, in Beyond Common Sense: Psychological Science in the Court-room (Blackwell Publishing, London, 2008).

[85] A. Kaatz, B. Guerrez, and M. Carnes, Threats to objectivity in peer review: The case of gender, Trends Pharmacological Sci. 35, 371 (2014).

[86] J. C. Blickenstaff, Women and science careers: Leaky pipeline or gender filter?, Gender Educ. 17, 369 (2005).

[87] J. R. Cimpian, T. H. Kim, and Z. T. McDermott, Understanding persistent gender gaps in STEM, Science $\mathbf{3 6 8}$, 1317 (2020).

[88] GENERA (Gender Equality in Physics in the European Research Area) network, https://www.genera-network.eu/. 